\title{
Secuencia de cierre en conversaciones telefónicas
}

\author{
Carmen González Royo
}

\begin{abstract}
This paper is based on a corpus of 11 phone conversations in Italian and 15 in Spanish. These are transactional conversational encounters and there is no confidential relationship between the speakers, nor does the topic deal with private subjects.

I mainly contrast pragmatic and communicative aspects from these examples in both languages, specially about the turn taking system, strategies and conversational routines that are used by the participants to these conversations in the closing section.
\end{abstract}

\section{Introduccion: el corpus}

M e centraré en el análisis de la fase de cierre en las conversaciones telefónicas

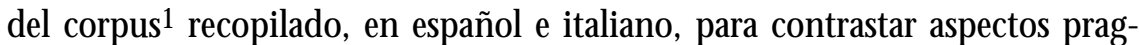
máticos y comunicativos. Se examinarán las estrategias conversacionales y las rutinas correspondientes que los hablantes han utilizado dentro del sistema de toma de turnos, en función de las peculiares condiciones en que tiene lugar la conversación tel efónica, ${ }^{2}$ caracterizada por ser un intercambio, generalmente, diádico limitado al canal sonoro que debe mostrar con claridad la apertura y - preferiblemente- también el cierre en ausencia absoluta del código gestual.

1. Signos utilizados en la transcripción de los textos:

$\begin{array}{llll}: & \text { Identificación hablantelinicio turno } & \wedge & \text { Acento principal } \\ \text { [ ] } & \text { Solapamiento } & 1 & \text { Acento secundario } \\ \text { Final } & ! & \text { Reforzamiento } \\ \text { ? } & \text { Continua } & = & \text { Alargamiento } \\ \text { I Interpelación } & \text { Subida tono } & (0) & \text { Cierre } \\ \text { idad de voz: } & \varangle \mathrm{x}> & \text { Escucha dudosa } \\ \varangle \mathrm{F}>\quad \text { Fuerte } & \varangle \mathrm{D}>\text { D eprisa } \\ \varangle \mathrm{B}>\text { En voz baja } & \end{array}$

2. Para este tema me remito a los trabajos de Schegloff (1968), Schegloff-Sacks (1973), Levinson (1983: 284-369), Poyatos (1980), H opper (1991) y H outkoop-Steenstra (1991). 
El corpus seleccionado para esta comunicación está formado por una serie de conversaciones telefónicas no censuradas: 11 en italiano y 15 en español, con una duración que oscila entre los $25 \mathrm{seg}$. y los $5 \mathrm{~min}$. Todas han sido captadas de principio a fin de la interacción.

El equipo técnico lo constituye una sencilla grabadora a la que se le ha aplicado un micrófono de ventosa para teléfono. El interlocutor (emisor o receptor) que se halla al otro lado del hilo desconoce que su conversación esté siendo registrada, y se ha mantenido ese carácter clandestino. ${ }^{3}$ Para los interlocutores avisados tiene mayor peso el hecho real de que la conversación es auténtica en todas sus consecuencias que la propia presencia del magnetofón. Los interlocutores mantienen una relación que se ve limitada por unos intereses profesionales o comerciales y, en muchos casos, no se conocen, lo que les obliga a una formalidad más o menos evidenciada. Los roles que desempeñan los definen los dobletes cliente-vendedor o usuario-empleado. Así, pues, puede hablarse de muestra espontánea para un determinado contexto de carácter transaccional. En cuanto al tópico base de la conversación, gira alrededor de solicitar información acerca de precios, detalles de un producto o servicio 0 también sobre la presencia de alguien en un domicilio o lugar de trabajo.

\section{Secuencia de cierre}

La vertiente práctica del encuentro conversacional y las normas que rigen la prioridad impiden que se dé por cerrada una conversación sin que los interlocutores hayan dispuesto de su derecho a introducir nuevos tópicos o a terminar completamente los mencionados. Los precierres ${ }^{4}$ están ligados a las secuencias de cierre y funcionan como avances de las mismas. U na vez aceptado por parte de ambos interlocutores el final de la conversación (por tanto, han reconocido las marcas de precierre como tales) se da paso a la fase de cierre ${ }^{5}$ propiamente dicha. En este momento ya no se introducen nuevos tópicos, sí, en cambio, puede ser una ocasión para recapitular sobre lo dicho, fijar futuros contactos, agradecer, saludar, etc.

La sección de cierre ${ }^{6}$ queda articulada por la actuación colaborativa de los interlocutores, sobre la base de una estructura de pares adyacentes. Si, por un lado, este sistema puede llevar implícito al gún problema de carácter técnico y social, ${ }^{7}$ por otro, posee también la forma de resolverlo: el carácter intrínseco de los pares adyacentes informa a los participantes que tras una $1^{\text {a }}$ parte sucede, 0 debería suceder, una 2a.

3. Véase a este respecto Stubbs (1983: 219).

4. Schegl off-Sacks (1973: 303-309) consideran los precierres como un elemento de la secuencia de cierre. AndréL arouchebouvy (1983: 99) lo denomina épilogue.

5. Levinson (1983: 325) hace referencia a las condiciones que determinan la eficacia de una secuencia de cierre.

6. Levinson (1983: 317) enumera los elementos esenciales en la secuencia de cierre.

7. Levinson (1983: 316, 324) y Schegloff-Sacks (1973: 325). 


\subsection{Precierres}

Las ofertas de cierre en conversaciones monotópicas, 8 como gran parte de las Ilamadas de este corpus, hace que - una vez cerrado el tópico - ambos interlocutores lleguen a considerar necesaria la clausura del encuentro y este hecho suele ser aceptado sin reaperturas por parte de ninguno de ellos. Es, tal vez, más evidente la ocasión de cierre.
(1) C: Cientoveinticincobê. Ahora entro y se lo digo, vale? INICIO
B: Sí, RESPUESTA
gracias.
(2) B: Vabene,
allora ci sentiamo verso le due e mezza
A: Vabene, d'accordo, la ringrazio eh? Arrivederci.
B: [Arrivederci.] (0)

Antes, sin embargo, de que ambos interlocutores acepten un precierre como definitivo puede haber tenido lugar una sucesión de intentos fallidos por parte de alguno 0 ambos interlocutores que los ha convertirlo en reapertura:

En (3) T 89, B inicia la cadena de cierre que se ve truncada por la reapertura de $C$ en T90. Los siguientes turnos de paso de B no son considerados por su interlocutor como precierres y será $\mathrm{C}$ quien dé por concluido el encuentro con vale y su saludo, en T94. En la conversación en italiano (4) se ven idénticos comportamientos.

(3)

T89 B: D e acuerdo. Gracias.

T90 C: A ver si yo trato de, de obtener unos $\varangle$ dâtos $F>$.

T91 B: M uy bien.

T92 C:y con esos datos a lo mejor ya puedo hablar mejor con usted.

T93 B: Eso es. Sí, sí, sí.

T94 C: Vale.

$\mathrm{H}$ asta ahora.

T95 B: Gracias.

Adiós, hasta luego.(0)
(4)

T46 B: Certo.

T47 A: Vabene! Allora, mi fai sapere qualcosa verso lunedì o martedi?

T 48 B: Penso senz'altro.

T49 A: O K, Sì, per lunedì o martedì.

così posso cercare qualche altra cosa.

T50 B: xxxxxx

T51 A: Va bene?

T52 B: OK!

T53 A: Grazie! Buon fine settimana.

T54 B: Be', grazie, anche a te.

Ciao, ciao! (0)

Las rutinas de precierre son turnos de paso con rutinas que expresan conformidad, acuerdo, con respecto a lo dicho hasta el momento y, en algún caso, introducen los datos de un encuentro futuro (V éase 2). 
En español se han encontrado las expresiones de acuerdo, muy bien, perfecto o nada (a veces con el inicio apositivo pues) pero con mucha mayor frecuencia la expresión vale. Vale y de acuerdo se han construido también en forma de par en el que la 2a parte repite la emisión de la primera o han tomado la forma de Inicio/Respuesta (I/R). Estas fórmulas pueden combinarse para marcar más claramente el ofrecimiento de precierre: Perfecto, muy bien, por ejemplo.

En italiano, con esta misma función, se recogen d'accordo, okay, benissimo, bene, va bene, construidas también, a veces, con estructura de par I/R como en (4) T 51. M e remito a transcripciones anteriores para ampliar la estructura de las rutinas de precierre en italiano. Como inicio apositivo, semejante al pues español, aparece allora (véase 2 y 6).

\subsection{Secuencia de cierre: el sistema de turnos. estrategias y rutinas dela secuencia de cierre}

En la fase de cierre aparecen combinadas rutinas de agradecimientos, expresión de deseos positivos hacia el otro o disculpas con saludos. ${ }^{9}$ Si bien la prioridad requeriría que se emitieran las $2^{a}$ partes de par no es una exigencia respetada siempre por los interlocutores: se responde a todas 0 a algunas de las primeras partes aunque el resultado de cierre es eficaz.

0 no se replica al agradecimiento, como en (2) o bien se omite la 2a parte del saludo de despedida como en los ejemplos siguientes:

(5)
B: M uy amable.
M uchas gracias.

A: De nada.

Adiós. (0)
(6) B: Okay, Grazie.

A: Prego, arrivederci. (0)

\subsubsection{Agradecimientos ${ }^{10}$}

Con esta estrategia en el cierre se agradece al interlocutor la amabilidad de haber atendido a la llamada, la información aportada, el servicio que ha prestado, etc.

9. «... les répliques sont échangées sur un rythme rapide et les séquences les plus longues ne fournissent qu'une agréable impression de complétude». (AndréLarouchebouvy, 1984: 103)

10. Coulmas (198: 70 y ss.) aporta un elenco deejemplos de pares deagradecimiento y disculpa en inglés, francés, alemán y griego en los que las respuestas a la primera emisión de ambas estrategias coinciden con sus rutinas más básicas. En italiano hallamos, deacuerdo con ello, grazie/prego (o niente con menor frecuencia en los textos grabados) y también scusi/prego (o niente). En español los pares gracias / de nada no se corresponden con tanta evidencia con perdone/de nada (realizado en 14, en la réplica aparece también a mandar), hemos verificado que o no se responde directamente a la disculpa (13), o se utilizan otras respuestas de alivio al interlocutor como (no es) nada. Agradecimientos y disculpas convergen, sin embargo, cuando la réplica es no hay de qué. D e todos modos, concuerdan en el valor atenuativo con que el emisor de la segunda parte del par adyacente mitiga (o intenta mitigar) la primera emisión. 
Su estructura mantiene la característica de las otras estrategias propias de las secuencias marco: los pares adyacentes:

(muchas) gracias/de nada, en español, o grazie (tante)/prego, en italiano, serían las dobletes más frecuentes, en los que el segundo término tiende a minimizar el gesto expresado a su favor por el primero. La fórmula, 2a parte del par, N 0 hay de qué es semejante a de nada. Gracias sería también su correspondiente 1 a parte.

(7)
B: Gracias.
A: De nada=1.
Adiós. (0)

(8) B: Grazie!

A: Pre=go! (0)

Con la repetición de la primera rutina del par de agradecimiento, el segundo emisor coloca a su interlocutor en el mismo lugar y tal agradecimiento es recíproco. Se han encontrado estos dobletes: muchas gracias/G racias y gracias/D e acuerdo, pues, muchísimas gracias, eh!, en el primero es la entonación ascendente lo que equipara el segundo al primer término con su énfasis; en el último doblete el adverbio no sólo hace que se devuelva el gesto sino que lo hace aumentándolo.

0 tro recurso que resuelve la réplica a la primera parte del par es devolver el agradecimiento al interlocutor que ha iniciado la estrategia. En los datos del corpus se trata de relaciones del tipo cliente / empleado, siendo el primero quien agradece y el segundo quien da la contrapartida en un agradecimiento recíproco.
(9) C: Gracias.
B: A usted. (0)

(10) B: M olte grazie

A: Anche alei/

arrivederci, buongiorno. (0)

0 tros casos hallados en medio de otra cadena de la tase de cierre son: Gracias/D e nada, a tí (en la segunda parte se minimiza el hecho que merece agradecimiento y se compensa al otro interlocutor devolviéndole el gesto) y gracias/A tí, en los datos en español. D e forma semejante se comportan los hablantes italianos en: M olte grazie/Anche a lei o bien la 2ª parte a te de (2).

En otros finales, como son los siguientes, A no es correspondido con la réplica a la primera rutina en la segunda parte del par. Se da por cerrada también la secuencia de este modo:
(11) A: O igame, no contestan, eh!
B: Gracias. (0)
(12) A: Sta arrivando, Eh!
B: H um! sta arrivando? Grazie.

O tra tormula que expresa agradecimiento en italiano es: la ringrazio y requeriría - por prioridad- una segunda rutina que quitara relevancia al 
hecho por parte del receptor del agradecimiento, del tipo niente, prego o igualar al interlocutor con un sentimiento recíproco.

\subsubsection{D eseos}

Expresar deseos positivos al interlocutor se produce en muy raras ocasiones entre desconocidos y en este corpus de encuentros telefónicos se han preferido otras estrategias de cierre que no hicieran referencia directa al territorio individual, más neutrales. (4) es una excepción: a juzgar por el tono de la conversación, A y B se conocen personalmente, con toda seguridad, tampoco es la primera vez que entran en contacto. A en (4) T53 (A: G raziel Buon fine settimana.) se permite la «intimidad» de aludir al fin de semana de su interlocutor $B$, que responde con la réplica en T 54 ( $B$ : Be', grazie, anchea te. Ciao, ciao! (0)).

A ha utilizado este elemento con función de saludo de despedida y en su lugar. C omo puede apreciarse en la respuesta, B agradece el deseo positivo de A hacia él mismo y lo propone a su vez a la interlocutora al tiempo que cierra definitivamente con la repetición de un saludo cordial y con el rasgo «familiar».

Puede hablarse también aquí de cadena de elementos de cierre: A agradece y desea buenos momentos a $B$ que le devuelve el agradecimiento - que puede referirse también a los deseos- y los buenos deseos además de saludarla informalmente con la rutina Ciao, ciao! (0).

\subsubsection{D isculpas}

O tra estrategia observada dentro de la fase de cierre ha sido la disculpa que sintetiza el sentimiento del emisor que ha cometido un error, en este caso de receptor, y se siente en el deber de excusarse por ello. En (13) el segundo par de la disculpa es una rutina de saludo de despedida.
(13) A: Ah, perdón.
B: Adiós. (0)

(14) B: Vaya!, pues, nada, perdone.

A: D e nada, mujer, a mandar. $\ll \mathrm{H}$ astaluego $=\mathrm{D}>$.

B: $\varangle$ Adiós, buenos días. $D>$. (0)

En (14) las disculpas se ven minimizadas por la emisión del receptor, más explícito que el anterior, que emite una cadena de rutinas para aliviar el primer elemento del par de B. A emplea un vocativo, aproximándose a su interlocutora, ofrece su disponibilidad y acaba abriendo un par adyacente de saludo de despedida.

El carácter rutinario de estos turnos queda patente en la velocidad con que ambos interlocutores lo producen, sin dar tiempo al otro para que emita las segundas partes previsibles del par iniciado (V éase nota 9). N o hacerlo, sin embargo, crearía un intercambio no cortés aunque posible ya que el anonimato de ambos quedaría siempre garantizado y a salvo su imagen personal.

En italiano no se dispone de ejemplos para esta estrategia. 


\subsubsection{Saludos}

Los saludos de despedida que preceden inmediatamente al acto de colgar el teléfono, y que no han aparecido combinados con rutinas como el agradecimiento u otras, demuestran una perfecta estructura de pares adyacentes en los que la primera parte del par es repetida dando lugar a la segunda emisión del mismo, en calidad de respuesta, como en (15). En (16), en cambio, el emisor de la segunda parte del par adyacente opta por sustituir la respuesta eco con otra fórmula de saludo diferente, sin alterar el esquema previsible:

(15) A: [Vale, muy bien.]

B: Adiós.

$A:<B$ Adiós $B>$. (0)
(16) C: V ale, de acuerdo.

$\mathrm{H}$ asta luego

B: Adiós. (0)

0 tros ejemplos de réplicas eco encontradas son:

$\mathrm{H}$ asta pasao mañana/H asta pasao mañana; $\mathrm{H}$ asta ahora!/H asta ahora; $\mathrm{H}$ asta luego./H asta luego=/, en español y Arrivederci/Arrivederci en italiano.

Grazie, buonasera/Ciao es otro par presente en el corpus que altera la repetición de la emisión del interlocutor y se decide por otra rutina menos formal.

El interlocutor que cierra la conversación con un saludo puede ser tanto el receptor - en el último ejemplo - como el emisor de la llamada - en los anteriores-. Sería el que antes se encuentre en el punto a que lo aboca el último turno después del precierre.

La acumulación de saludos que se observa en algunas emisiones incre menta la fuerza de las mismas quedando patente su uso fático:

En español: Adiós/H asta luego, adiós, H asta luego/Adiós, adiós, y en italiano: Arrivederci, buongiorno!/0; Ciao, ciao!/0.

\section{Conclusión}

Las conversaciones analizadas, en español e italiano, comparten las circunstancias extralingüísticas mencionadas al hablar del corpus. I gualmente, en el capítulo 2, se indicaba el val or y el sentido de la secuencia de cierre en cuanto síntesis de un encuentro y nexo referencial para otros hipotéticos encuentros futuros. Ello determina la presencia de ciertas estrategias en las que prevalecen las manifestaciones d ela cortesía. Como sucede en las secuencias estereotipadas, la relación entre interlocutores es la que mediatiza la elección de una u otra fórmula para la despedida.

Es evidente que las secciones de cierre se construyen a partir de la actitud colaborativa de los participantes, por lo que el análisis de las rutinas de cierre 
aisladas, fuera de su estructura conversacional, pierde la capacidad de mostrar su estructura intrínseca.

Los datos del corpus nos aportan, por un lado, información acerca de la producción lingüística de los usuarios en este tipo de conversaciones telefónicas sobre estrategias y rutinas utilizadas en los cierres. Por otro lado, las secuencias de cierre de estas conversaciones nos sirven como propuesta para establecer una equivalencia pragmática entre textos, en ambas lenguas, que tiene en cuenta el registro, la relación funcional entre interlocutores, la intencionalidad del emisor y criterios de uso de las emisiones.

\section{Bibliografía}

AN dRÉ-LaRo u Chebouvy, D. (1984). La conversation quotidienne Paris: Didier.

Cheepen, Ch. (1988). The Predictability of Informal Conversation. Oxford: Pinter Publishers.

Coulm AS, F. (ed.) (1981). Conversational Routine. The H ague: M outon.

Du BoIs, J.W . (1991). «T ranscription design principles for spoken discourse research». Pragmatics Antwerp: IPRA: 71-106

GaLLARD o-PAú LS, B. (1993). Lingüística perceptiva y conversación: secuencias Valencia: Lynx. Biblioteca Facultat de Filologia.

- (1996). Análisis conversacional y pragmática del receptor. V alencia: Ediciones Episteme.

GonzÁlez Royo, C. (1996). Secuencias marco en textos deíndole transaccional: Análisis contrastivo español-italiano. U niversitat de $V$ alència, inédita.

H OPPER, R. (1991). «H old the Phone». En Boden-Zimmerman. Talk and Social Structure. Cambridge: Polity Press.

H OUtKo O P-Steenstra, H . (1991). «O pening Sequences in D utch Telephone Conversations». En Boden-Zimmerman. Talk and Social Structure. Cambridge: Polity Press.

Kerbrat-Orecchioni, K. (1990). Les interactions verbales. París: Armand Colin, vol. I.

LEVIN SO N, S. (1983). Pragmatics. Cambridge: U niversity Press.

N ORD, Ch. (1994). «T raduciendo funciones». En HuRTAD o ALBIR, A. (ed.). Estudis sobre la traducció. C astellón: Publicacions U niversitat J aume I: 97-112.

PoyATOS, F. (1980). «nteractive functions and limitations of verbal and non verbal behavior in natural conversations». Semiotica (58:1/2): 29-40.

- (1994). La comunicación no verbal. M adrid: Itsmo.

SCHEGLOFF, E. (1968). «Sequencing in conversational openings». En FISH M AN, (ed.). Readings in the sociology of language. The H ague: M outon: 91-125.

Schegloff, E.; SAcks, H. (1973). «O pening up closings». Semiotica (8.4), p. 289-327.

Stubbs, M . (1983). Análisis del discurso. M adrid: Alianza Psicología.

VENTOLA, E. (1979). «T he structure of casual conversation in Englis. J ournal of Pragmatics (3): 267-298.

Voguera, M . (1992). Sintassi eintonazione dell'italiano parlato. Bologna: II M ulino. 